\title{
Surface Evaluation of Enamel Etched by Er,Cr:YSGG Laser for Orthodontic Purpose
}

\author{
Daniela S Lopes ${ }^{1}$, Daisa L Pereira², Claudia CBO Mota ${ }^{3}$, Luciana SA Melo ${ }^{4}$, Patricia A Ana ${ }^{5}$, Denise M Zezell ${ }^{6}$, \\ Anderson SL Gomes ${ }^{7}$
}

\begin{abstract}
Aim: To compare the effect of erbium, chromium:yttrium-scandium-gallium-garnet (Er,Cr:YSGG) laser at different irradiation parameters and acid etching on the shear bond strength (SBS) of orthodontic brackets to enamel.

Materials and methods: Forty bovine incisors were randomly distributed into groups ( $n=10)$ : Gl: 37\% phosphoric acid etching; GII: Er,Cr:YSGG laser etching $19.1 \mathrm{~J} / \mathrm{cm}^{2}$; GIII: Er,Cr:YSGG, $29.3 \mathrm{~J} / \mathrm{cm}^{2}$; and GIV: Er,Cr:YSGG, $42.4 \mathrm{~J} / \mathrm{cm}^{2}$. After treatments, metallic brackets were bonded using Transbond XT adhesive system. After light curing, the samples were subjected to 500 thermal cycles, debonded with a universal testing machine, and the SBS values were recorded. After debonding, surface morphology was evaluated using scanning electron microscopy (SEM) and optical coherence tomography (OCT). The values of SBS testing were analyzed by one-way analysis of variance (ANOVA) and Tukey post hoc test, at $5 \%$ significance level.

Results: The mean SBS values of Gl, GII, GIII, and GIV groups were $6.2 \pm 1.7 \mathrm{MPa}$, $4.6 \pm 2.5 \mathrm{MPa}, 7.0 \pm 2.2 \mathrm{MPa}$, and $8.0 \pm 3.6 \mathrm{MPa}$, respectively. Laser irradiation promoted rough surfaces in all parameters used, and the OCT analysis revealed higher optical changes on lased groups when compared with phosphoric acid.

Conclusion: $\mathrm{Er}, \mathrm{Cr}: Y S G G$ laser irradiation operated at $42.4 \mathrm{~J} / \mathrm{cm}^{2}$ and $29.3 \mathrm{~J} / \mathrm{cm}^{2}$ is a better alternative for etching enamel prior to the orthodontic treatment than the phosphoric acid.

Clinical significance: $\mathrm{Er}, \mathrm{Cr}$ :YSGG laser irradiation is better than the phosphoric acid for etching enamel prior to the orthodontic treatment because laser irradiation promotes similar SBSs and preventing demineralization around orthodontic brackets.

Keywords: Enamel conditioning, Er,Cr:YSGG laser, Laboratory research, Orthodontic brackets.

The Journal of Contemporary Dental Practice (2020): 10.5005/jp-journals-10024-2777
\end{abstract}

\section{INTRODUCTION}

Brackets are a fundamental part in the orthodontic treatment, and they must remain well fixed to the teeth throughout the therapy, which requires adequate conditioning, without secondary effects. The phosphoric acid represents the standard enamel conditioner in orthodontic practice, in which the aim is to prepare and to create an irregular surface that propitiates the adequate bonding of etchand-rinse adhesive systems. ${ }^{2}$ The main advantage of phosphoric acid etching is a high level of SBS is achieved. ${ }^{3}$

Alternative methods to prepare dental surfaces, such as laser irradiation, have attracted increasing attention since the first laser application reported in $1964 .{ }^{4}$ Among the high-power lasers, most used for dental applications is the erbium, chromium:yttriumscandium-gallium-garnet ( $\mathrm{Er}, \mathrm{Cr}$ :YSGG) laser, which emits at $2.78 \mu \mathrm{m}$ and is strongly absorbed in hard tissues due to its interaction with both water and $\mathrm{OH}^{-}$from hydroxyapatite at the tissue interface. ${ }^{5}$ Due to the ablation process, the tissue becomes more resistant to demineralization; also, laser irradiation promotes bacterial removal and reduces secondary caries lesion susceptibility increasing the success of the procedure.

It can be employed without creating a smear layer ${ }^{6}$ and can offer a similar bonding effect when compared with conventional acid etching, and roughening the surface can markedly increase the bonding area between the substrate and resin..$^{6-8}$

Considering that orthodontic treatment is often of long duration, another advantage promoted by Er,Cr:YSGG laser irradiation is the long-lasting protective effect against secondary caries, ${ }^{9}$ essential for the prevention of the white spot lesions
${ }^{1}$ Department of Prosthesis and Oral and Facial Surgery, School of Dentistry, Federal University of Pernambuco (UFPE), Recife-PE, Brazil

${ }^{2,6}$ Center for Lasers and Applications - Nuclear and Energy Research Institute (IPEN-CNEN/ SP), Sao Paulo-SP, Brazil

${ }^{3}$ Department of Dentistry, School of Dentistry, Caruaruense Association of Technical and Higher Education (ASCES), Caruaru-PE, Brazil

${ }^{4,7}$ Department of Physics, Federal University of Pernambuco (UFPE), Recife-PE, Brazil

${ }^{5}$ Center for Engineering, Modelling and Applied Social Sciences, Federal University of ABC (UFABC), Sao Bernardo do Campo-SP, Brazil

Corresponding Author: Anderson SL Gomes, Department of Physics, Federal University of Pernambuco (UFPE), Recife-PE, Brazil, Phone: +55 8121268000, e-mail: anderson@df.ufpe.br

How to cite this article: Lopes DS, Pereira DL, Mota CCBO, et al. Surface Evaluation of Enamel Etched by Er,Cr:YSGG Laser for Orthodontic Purpose. J Contemp Dent Pract 2020;21(3):227-232.

Source of support: CAPES/PROCAD 88881.068505/014-01, CNPq/INCT 465763/2014-6, CNPq-PQ 312397/2013-5 and CNPq 140619/2015-1

Conflict of interest: None

that may occur around the brackets during the orthodontic treatment.

Many factors are known to influence the effects of Er,Cr:YSGG laser treatment on dental hard tissues, such as the output power, energy density, the repetition rate, and cooling water-air ratio. ${ }^{10}$

Concerning the laser parameters used for enamel etching prior to the bonding of brackets, the literature is controversial, and it

() The Author(s). 2020 Open Access This article is distributed under the terms of the Creative Commons Attribution 4.0 International License (https://creativecommons. org/licenses/by-nc/4.0/), which permits unrestricted use, distribution, and non-commercial reproduction in any medium, provided you give appropriate credit to the original author(s) and the source, provide a link to the Creative Commons license, and indicate if changes were made. The Creative Commons Public Domain Dedication waiver (http://creativecommons.org/publicdomain/zero/1.0/) applies to the data made available in this article, unless otherwise stated. 
was not identified studies that relate the use of Er,Cr:YSGG for this purpose, which motivated the accomplishment of this study.

In this way, the objective of this study was to evaluate the effects promoted by Er,Cr:YSGG laser, when operated at different laser parameters aiming enamel etching for orthodontic purposes, through the following factors: the SBS, the adhesive remnant index (ARI), and the surface morphology of the enamel.

\section{Materials and Methods}

This study was approved by the Ethical Committee on Animal Experiments. The procedures for sample preparation were in accordance with the specifications of ISO/TS 11405:2015..$^{11}$ Forty freshly extracted bovine incisors were selected and stored in $0.5 \%$ chloramine-T solution during 48 hours for disinfection. The root portion of all teeth was removed, and the crowns had their buccal surface manually polished with sandpaper P600 (3M Unitek, USA) to reduce the grooves presented in bovine enamel. The specimens were included in a cylindrical support and embedded in acrylic resin, keeping the buccal surface parallel to the mold base. Specimens were stored in distilled water $\left(4^{\circ} \mathrm{C}\right)$ until bonding procedures. They were randomly distributed into four experimental groups $(n=10)$, according to Table 1.

For the control group, etching was performed with a $37 \%$ phosphoric acid gel (FGM Produtos Odontológicos, Brazil) for 15 seconds followed by a 15 -second water rinse. Specimens were airdried until a frosty white appearance was achieved.

Laser irradiation was performed with an Er,Cr:YSGG laser (Biolase Technology, Inc., USA), emitting at $2.78 \mu \mathrm{m}$ with $20 \mathrm{~Hz}$ repetition rate, and the pulse width was approximately $140 \mu \mathrm{s}$ for 15 seconds, at three different power settings (Table 2). A sapphire MZ6 tip of $600 \mu \mathrm{m}$ diameter and $6 \mathrm{~mm}$ length was used with $55 \%$ air and $45 \%$ water coolant. ${ }^{12}$

During the irradiation, the samples were positioned in a highprecision motorized translator (Newport, USA) $1 \mathrm{~mm}$ away from the laser tip adjusted to a speed of $3.8 \mathrm{~mm} / \mathrm{second}$, thus standardizing the irradiation condition.

Brackets for upper incisors with a $15.3-\mathrm{mm}^{2}$ base area were used (Dental Morelli, Brazil). Brackets were bonded according to

Table 1: Experimental design considering as main factors: adhesive system, substrate, and surface conditioning conditions

\begin{tabular}{lll}
\hline $\begin{array}{l}\text { Surface conditioning condi- } \\
\text { tions }\end{array}$ & Substrate & Adhesive system \\
\hline $\begin{array}{l}\text { Group I: etching with 37\% } \\
\text { phosphoric acid }\end{array}$ & Enamel & $\begin{array}{l}\text { Primer + Transbond XT } \\
\text { adhesive }\end{array}$ \\
$\begin{array}{l}\text { Group II: Er,Cr:YSGG laser } \\
\text { irradiation (1.1 W) }\end{array}$ & Enamel & $\begin{array}{l}\text { Primer + Transbond XT } \\
\text { adhesive }\end{array}$ \\
$\begin{array}{l}\text { Group III: Er,Cr:YSGG laser } \\
\text { irradiation (1.7 W) }\end{array}$ & Enamel & $\begin{array}{l}\text { Primer + Transbond XT } \\
\text { adhesive }\end{array}$ \\
$\begin{array}{l}\text { Group IV: Er,Cr:YSGG laser } \\
\text { irradiation (2.41 W) }\end{array}$ & Enamel & $\begin{array}{l}\text { Primer + Transbond XT } \\
\text { adhesive }\end{array}$ \\
\hline
\end{tabular}

Table 2: Laser irradiation conditions

\begin{tabular}{llll}
\hline Group & Power $(W)$ & Energy per pulse $(\mathrm{mJ})$ & Energy density $\left(\mathrm{J} / \mathrm{cm}^{2}\right)$ \\
\hline I & - & - & - \\
II & 1.1 & 54.1 & 19.1 \\
III & 1.7 & 83 & 29.3 \\
IV & 2.4 & 120 & 42.4 \\
\hline
\end{tabular}

the manufacturer's instructions (Table 3 ) and were positioned at the center of the buccal surface to simulate the clinical procedure. The excess of orthodontic cement was carefully removed before light curing. Photoactivation was performed using a light-emitting diode curing unit emitting $1,200 \mathrm{~mW} / \mathrm{cm}^{2}$ (Bayswater, Australia) for 10 seconds in each proximal side of the bracket (mesial and distal).

After 24 hours storage in distilled water at $37 \pm 1^{\circ} \mathrm{C}$, all specimens were thermocycled (Ética Equipamentos Científicos $\mathrm{S} / \mathrm{A}, \mathrm{Brazil})$. A total of 500 cycles of alternate baths $\left(5-55 \pm 2^{\circ} \mathrm{C}\right), 30$ seconds in each bath, and 2 seconds transfer time were performed.

Specimens were prepared for the SBS test, under a universal testing machine (Emic Equipamentos Industriais Ltda, Brazil) with a chisel at $0.5 \mathrm{~mm} /$ minute speed and $200 \mathrm{kgfload}$ cell.

To evaluate the SBS, the size of the bracket base has a meaningful importance, since the sustaining force increases as a function of the base area dimension. Therefore, the values were measured considering the rupture strength and the size of the bracket base. ${ }^{8}$ The debonding force $(F)$ was obtained in Newtons $(\mathrm{N})$ and the strength in megapascal (MPa).

After debonding, teeth were examined under a stereomicroscope at 20x magnification (Zeiss, Germany) and classified according to the ARI: ${ }^{13}$

- Score 0-no adhesive remnant left on the tooth;

- Score 1 -less than $50 \%$ adhesive remnant left on the tooth;

- Score 2-more than $50 \%$ adhesive remnant left on the tooth;

- Score 3-100\% adhesive remnant left on the tooth.

All specimens were submitted to scanning electron microscopy (SEM) (TM 3000; Hitachi, Japan) and OCT analysis before and after the acid or laser etching. The OCT system (Callisto SD-OCT; Thorlabs, Inc., USA) operates at $930 \mathrm{~nm}$ central wavelength, spectral bandwidth of $100 \mathrm{~nm}$, maximum output power of $5 \mathrm{~mW}$, axial resolution of $7 / 5.3 \mu \mathrm{m}$ (air/water), lateral resolution of $8 \mu \mathrm{m}$, maximum imaging depth at $1.6 \mathrm{~mm}$, and axial scan rate of $1.2 \mathrm{kHz}$, capturing two frames per second with $105 \mathrm{~dB}$ of sensitivity. Two-dimensional (2D) OCT images were captured with 2,000 columns $\times 512$ rows and $6 \mathrm{~mm}$ transversal scanning, while

Table 3: Adhesive system used in this study

\begin{tabular}{|c|c|c|c|}
\hline Material & $\begin{array}{l}\text { Manufacturer } \\
\text { batch number \# }\end{array}$ & Composition & $\begin{array}{l}\text { Application } \\
\text { mode }\end{array}$ \\
\hline $\begin{array}{l}\text { Primer }+ \\
\text { Transbond XT } \\
\text { adhesive }\end{array}$ & $\begin{array}{l}\text { 3M Unitek \# } \\
503325\end{array}$ & $\begin{array}{l}\text { Bisphenol A } \\
\text { diglycidyl ether } \\
\text { dimethacrylate } \\
\text { (10-20 wt\%); } \\
\text { bisphenol } \\
\text { A bis(2- } \\
\text { hydroxyethyl } \\
\text { ether) } \\
\text { dimethacrylate } \\
\text { (5-10 wt\%); } \\
\text { filler: silane- } \\
\text { treated quartz } \\
\text { (70-80 wt\%) }\end{array}$ & $\begin{array}{l}\text { The primer was } \\
\text { applied with } \\
\text { microbrush } \\
\text { and then } \\
\text { light cured for } \\
20 \text { seconds. } \\
\text { Transbond } \\
\text { XT adhesive } \\
\text { paste should } \\
\text { be applied on } \\
\text { the bracket, } \\
\text { positioned } \\
\text { over the tooth } \\
\text { surface, and } \\
\text { photoactivated } \\
\text { for } 10 \text { seconds } \\
\text { in each side of } \\
\text { the bracket }\end{array}$ \\
\hline
\end{tabular}


three-dimensional (3D) images were captured with $400 \times 400$ $\times 400$ columns in each of $X Z, Y Z, X Y$ axes. These two techniques complement each other in the morphological analysis, due to their very different spatial resolutions.

Descriptive statistics, means and standard deviation (SD), were calculated for each group. Statistical analysis was performed using GraphPad Prism 6 (GraphPad Software, USA). Multiple comparisons were performed for SBS values between groups using one-way ANOVA and Tukey post hoc test. For the ARI evaluation, Chi-square test was used. A 5\% significance level was adopted.

\section{Results}

Descriptive statistics for comparison of SBS scores are given in Table 4. Group IV yielded the highest mean SBS $(8.0 \pm 3.6 \mathrm{MPa})$, while the phosphoric acid had mean SBS of $6.2 \pm 1.7 \mathrm{MPa}$. Analysis of variance did not reveal statistically significant differences among the groups ( $p=0.1310$ ).

Adhesive remnant index scores are listed in Table 5, and Chisquare test showed no statistically significant differences among the four groups ( $p=0.5508$ ).

Figure 1 shows the SEM images of enamel surface after the acid etching and laser irradiation under different protocols. The

Table 4: Mean of shear bond strengths of four groups

\begin{tabular}{llll}
\hline & \multirow{2}{*}{$\begin{array}{l}\text { Number of } \\
\text { samples }\end{array}$} & \multicolumn{2}{c}{ Bond } \\
\cline { 3 - 4 } & 10 & Mean $(\mathrm{MPa})$ & SD \\
\hline Group I & 10 & 4.6 & 1.7 \\
Group II & 10 & 7.0 & 2.5 \\
Group III & 10 & 8.0 & 2.2 \\
Group IV & & & 3.6 \\
\hline
\end{tabular}

Table 5: Distribution of adhesive remnant index scores

\begin{tabular}{lrrrr}
\hline & \multicolumn{4}{c}{ ARI scores } \\
\cline { 2 - 5 } Group & \multicolumn{1}{c}{0} & 1 & 2 & 3 \\
\hline Group I & 9 & 1 & - & - \\
Group II & 10 & - & - & - \\
Group III & 9 & 1 & - & - \\
Group IV & 10 & - & - & - \\
\hline
\end{tabular}
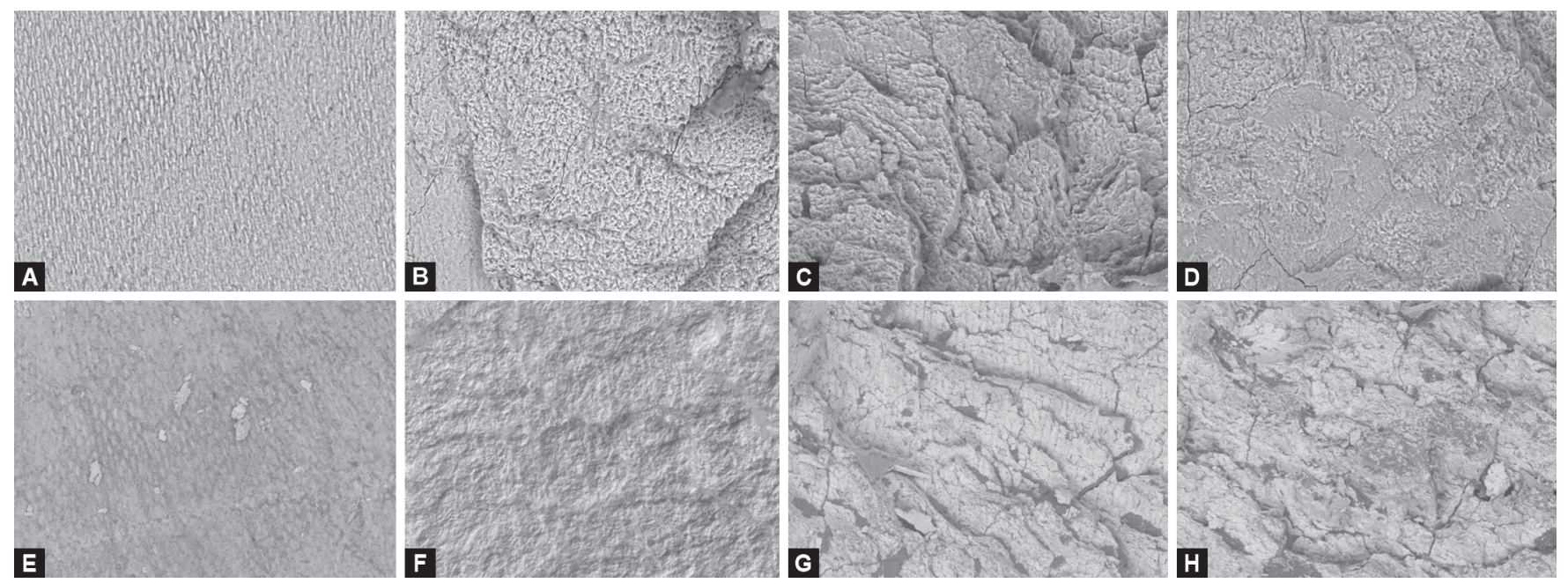

Figs $1 \mathrm{~A}$ to $\mathrm{H}$ : Electron micrographs of enamel after etching $(A$ to $D)$ and after ( $E$ to $H)$ debonding at $1,000 \times$ magnification. Arrows evidence the fragments of the adhesive system treatment with $37 \%$ phosphoric acid produced qualitatively rough surfaces in a pattern way, due to the dissolution of prisms and boundary regions. The laser-ablated surfaces of all experimental groups of this study presented depressions with fissures and conical craters and sharp enamel projections, without evidence of melting or carbonization. All laser-treated surfaces were accompanied by the appearance of slight dehydration cracks that can aid the penetration of resin. After debonding, it was possible to observe the presence of fragments of the adhesive system in all images. Also, all samples presented qualitatively rough surfaces, and laser-ablated ones presented higher projections, depressions, and cracks when compared with the surface conditioned with the phosphoric acid.

The optical characteristics of enamel after conditioning and after debonding by representative OCT images are shown in Figure 2. In sample conditioned with phosphoric acid, an intense backscattered signal at the enamel surface, represented by a bright zone, and darkened regions below the surface, which correspond to the loss of signal with increasing depth into the sample, are observed. After laser irradiation, the OCT images showed irregularities on the surface, which were more intense with the increase in laser energy density. The subsurface regions presented bright areas interspersed with dark areas, and these regions energy density. These irregularities in the backscattered signal from the subsurface of lased samples decreased after debonding, in which a decrease in bright areas is observed when compared with samples after irradiation.

\section{Discussion}

In this study, the effect of phosphoric acid etching or laser irradiation on surface characteristics, SBS values of brackets, and ARI scores was evaluated.

The etching of enamel with Er,Cr:YSGG laser for orthodontic purposes has several advantages, mainly considering the temperature rises promoted by laser irradiation on the enamel surface. ${ }^{14}$ The heating promoted by laser irradiation is enough to change the crystallinity and composition of enamel (such as the elimination of carbonate, the increase in the hydroxyapatite crystals, and the formation of new crystalline phases), and these changes can appeared in greater quantity in the samples irradiated with higher 

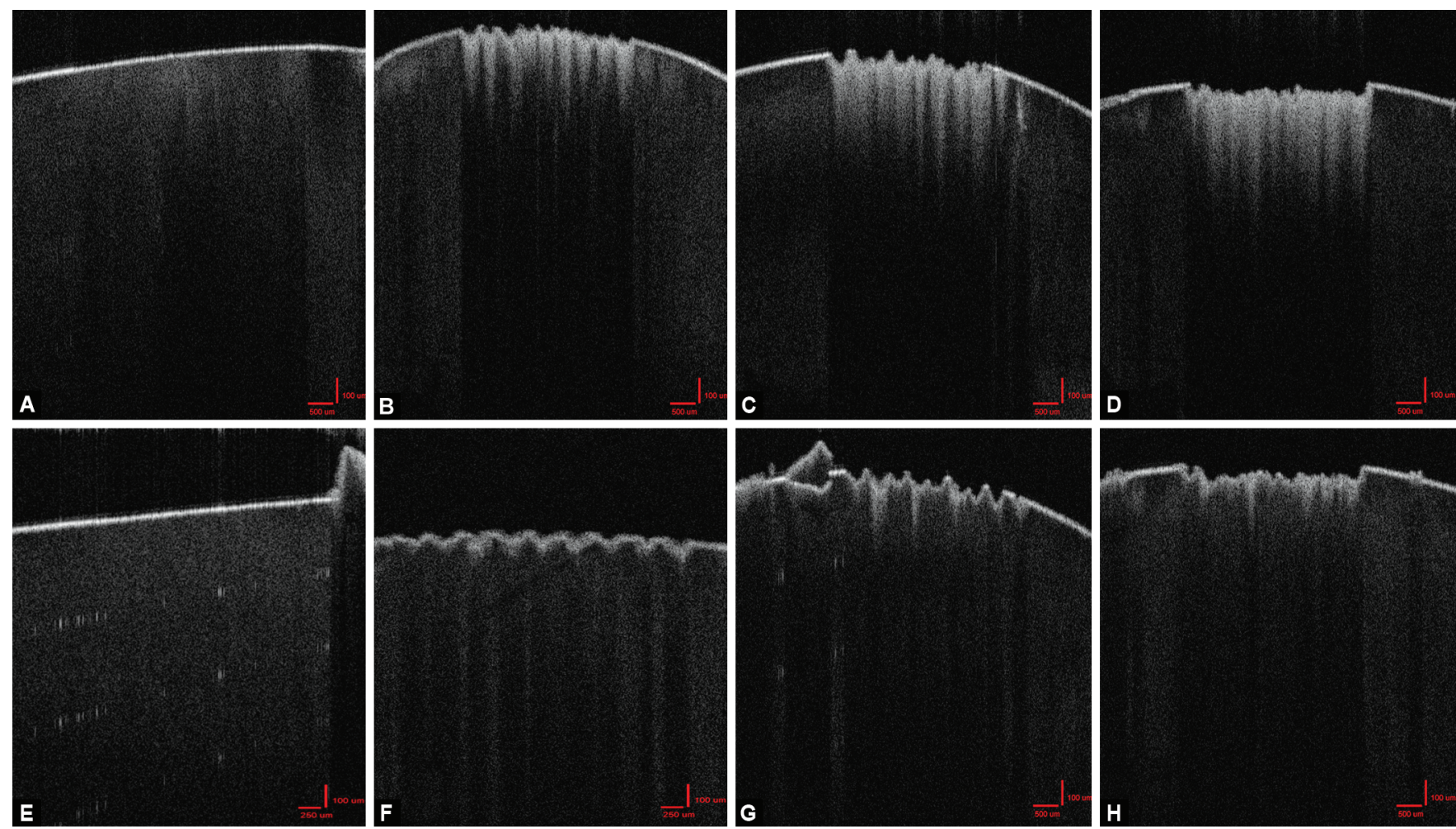

Figs $2 \mathrm{~A}$ to $\mathrm{H}$ : Optical coherence tomography images of enamel after conditioning ( $\mathrm{A}$ to $\mathrm{D}$ ) and after debonding (E to $\mathrm{H}$ ). The arrows correspond to the less-intense backscattered signal

be responsible to increase the resistance of laser-etched enamel to the development of early caries lesions. ${ }^{15}$

The removal of material using erbium lasers occurs by thermal ablation. In this process, the absorption of laser irradiation by bounded water molecules in the hard tissue leads to a temperature increase that promotes their microexplosions. To achieve ablation in any material, the laser energy density must be adjusted so that it is above the ablation threshold. ${ }^{15}$

This study determined the SBS of brackets to enamel and the surface characteristics of enamel etched, comparing with different output power of Er,Cr:YSGG laser, using the Transbond XT bonding system, considered as the "gold standard" for this clinical application. $^{6}$

We found the highest bond strength value in the 2.41-W laseretched group (GIV) $(8.0 \pm 3.6 \mathrm{MPa})$. This result is in accordance with the findings of Basaran et al., ${ }^{6}$ which worked with power output between $0.5 \mathrm{~W}, 1 \mathrm{~W}$, and $2 \mathrm{~W}$. In the case of this study, $4.34 \pm 3.16 \mathrm{MPa}, 9.88 \pm 4.43 \mathrm{MPa}$, and $11.14 \pm 4.75 \mathrm{MPa}$, respectively, were obtained and with brackets bonded with Transbond XT.

Reynolds reported that adequate bond forces in orthodontics range from 6 to $8 \mathrm{MPa} .{ }^{16}$ This in vitro study demonstrated that mean bond strength values of GIII and GIV groups remained within this range.

When the morphological effects of Er,Cr:YSGG lasers on dental tissues were examined, this research showed that all laser parameters used (GII, GIII, and GIV) were able to promote higher morphological changes on enamel than the acid etching (GI). Scanning electron microscopy images revealed that the morphological changes have a positive relation with the energy density used. The acid-etched sample had regular and slight grooves visible, whereas the laser groups created uneven and heterogeneous surface characteristics with microcracks in SEM analysis, as observed in Figure 1.

The OCT analysis supported the findings of SEM evaluation. The ability to reveal the enamel morphology without sectioning or dehydrating the samples is a significant advantage of OCT. Due to this fact, the feasibility of OCT to evaluate the effects of laser irradiation on optical characteristics of enamel when used for etching was also evaluated. In this study, the SEM and OCT images were acquired to allow the visual evaluation of the groups and characterization of enamel structure after debonding (Fig. 2). The SEM explored dental surface analysis. Optical coherence tomography provides cross-sectional tomographic imaging of tissue microstructures, carrying structural information of the biological sample by the reflected and backscattered light from the tissue within a penetration depth of $\sim 1 \mathrm{~mm}$ in enamel. ${ }^{17-19}$

By analyzing the OCT images after enamel etching, it is possible to observe the loss of the backscattered signal in the subsurface of enamel after phosphoric acid application, which can be due to chemical effects of phosphoric acid. After debonding, however, the subsurface is uniform and does not present the loss of backscattered signal. This fact occurred most probably due to the primer application, which penetrates the micropores of enamel after surface conditioning and changed its optical properties. $^{20}$

However, in the laser-treated groups, the subsurface of the tissue appears brighter in OCT images obtained immediately after laser irradiation. This aspect can be due to the thermal effects of laser irradiation, as well as the qualitatively roughness promoted, which increase with the augment of energy density and scattering, confirmed by the literature data, ${ }^{1,2,4,5}$ which also presented a positive relation with energy density in this study. The OCT images 
also show that the roughness promoted by laser irradiation, at any energy density, is higher than that promoted by phosphoric acid, which agrees with the findings observed by the SEM analysis. These aspects were more indicative of microexplosion than of melting, and some microcracking may occur as a result of local thermal stresses induced during the irradiation process. If the appropriated parameters for the laser radiation are properly used, there is no expected or reported side effects, particularly due to the fact that the laser beam used is a nonionizing radiation.

After debonding, the brighter aspect of subsurface of laseretched samples is almost fully missed; however, the surface remains rough. This finding can be also due to the primer penetration in the subsurface, which promoted chemical changes on enamel and, in this way, changed its optical aspect in the same way that occurred in samples that were conditioned with phosphoric acid. Therefore, the OCT analysis allowed the observation that the primer adsorption is similar on phosphoric acid- or laser-treated enamel. The primer penetration has a positive effect on adhesion of brackets, and this fact is supported by the SBS values obtained in this study. The ARI most prevalent score was 0 , demonstrating that shear occurred mainly between the dental surface and the adhesive system. The laser-treated groups, particularly groups II and IV, presented the largest number of specimens classified as score 0 when compared with the other groups. The evaluation of the ARI scores did not show statistically significant difference in the sites of link failure among the groups.

This result, which agrees with earlier studies, leads to the conclusion that the adhesive failure between the enamel and the bonding system is advantageous ${ }^{15}$ because there will be less adhesive remnant and, consequently, less time will be spent to remove it, besides a reduced chance of excessive wear. Bishara et al. argue that bond failure within the adhesive or at the bracketadhesive interface is more desirable than failure at the enameladhesive interface, because it might lead to enamel fracture and risk reduction of cracks while debonding. ${ }^{21}$ However, this would lead to longer clinical time, which is not desirable.

This study is a preliminary step toward incorporating laser in routine dental practice for orthodontic purpose and was carried during 4-6 months. After that, no further measurements were taken. Further in vitro and long-term clinical studies at different power settings and studies including variables like microleakage and bond strength in human teeth will provide additional information important for the efficacy of this laser clinically. There are, in principle, no technical limitations or side effects for this use of laser.

In this way, considering the findings observed in this study, we can consider that laser irradiation is an efficient method for enamel conditioning prior to the orthodontic treatment, presenting similar effects on bond strength to brackets when compared with phosphoric acid and presenting the advantage of decontamination of enamel surface and preventing a future demineralization around brackets, which is a serious and common deleterious effect on orthodontic treatments. The cost-benefit of using laser sources is still debatable, but scientifically, it is a tool to be considered for clinical purposes.

\section{Conclusion}

- $\quad \mathrm{Er}, \mathrm{Cr}$ :YSGG laser pulse repetition rate and output power are important parameters that might have significant effects on bond strength to irradiated enamel. The mean SBS and enamel surface etching obtained with $\mathrm{Er}, \mathrm{Cr}$ :YSGG laser operated at $42.4 \mathrm{~J} / \mathrm{cm}^{2}(2.41 \mathrm{~W})$ and $29.3 \mathrm{~J} / \mathrm{cm}^{2}(1.7 \mathrm{~W})$ is higher compared with that obtained with acid etching and could be considered clinically acceptable.

- The evaluation of ARI scores demonstrated no statistically significant difference in bond failure site among the groups, which suggest that laser irradiation can be used for enamel etching considering the advantages promoted by laser irradiation when compared with the phosphoric acid.

- Laser irradiation promoted higher roughness and optical changes on enamel when evaluated by the OCT technique. In this way, OCT is a promissing tool for future clinical evaluation of laser effects on enamel surface.

\section{Clinical Significances}

$\mathrm{Er}, \mathrm{Cr}$ :YSGG laser irradiation is better than the phosphoric acid for etching enamel prior to the orthodontic treatment because laser irradiation promotes similar SBSs and prevents demineralization around orthodontic brackets.

\section{Acknowledgments}

Authors are thankful to CAPES, for scholarship of DSL. This study was supported by CAPES/PROCAD 88881.068505/2014-01, FAPESP 17/50332-0, CNPq/INCT 465763/2014-6, CNPq-PQ 309902/2017-7, and CNPq 140619/2015-1.

\section{References}

1. Kim JH, Kwon OW, Kim H, et al. Acid resistance of erbium-doped yttrium aluminum garnet laser-treated and phosphoric acidetched enamels. Angle Orthodontist 2006;76(6):1052-1056. DOI: 10.2319/11405-398.

2. Pashley $\mathrm{DH}$. The effects of acid etching on the pulpodentin complex. Operative Dent 1992;17(6):229-234.

3. Horiuchi S, Kuroda S, Hiasa M, et al. Reinforcement of bond strength of self-etching orthodontic adhesive. Angle Orthod 2012;82(1):30-35. DOI: 10.2319/012011-39.1.

4. Stern RH, Sognnaes RF. Laser beam effect on dental hard tissues. J Dent Res 1964;43:873-873.

5. Kohns P, Zhou P, Störmann R. Effective laser ablation of enamel and dentine without thermal side effects. J Laser Appl 1997;9(3):171-174. DOI: $10.2351 / 1.4745457$.

6. Basaran G, Ozer T, Berk N, et al. Etching enamel for orthodontics with an erbium, chromium:yttrium-scandium-gallium-garnet laser system. Angle Orthod 2007;77(1):117-123. DOI: 10.2319/120605426R.1.

7. Lee BS, Hsieh TT, Lee YI, et al. Bond strengths of orthodontic bracket after acid-etched er:YAG laser irradiated and combined treatment on enamel surface. Angle Orthod 2003;73(5):565-570. DOI: 10.1043/0003-3219(2003)073<0565:BSOOBA>2.0.CO;2.

8. Botta SB, Ana PA, Zezell DM, et al. Adhesion after erbium, chromium:yttrium-scandium-gallium-garnet laser application at three different irradiation conditions. Lasers Med Sci 2009;24(1): 67-73. DOI: 10.1007/s10103-007-0521-3.

9. Quinto JrJ, Amaral MM, Francci CE, et al. Evaluation of Intra root canal Er,Cr:YSGG laser irradiation on prosthetic post adherence. J Prosthodont 2017; 1-5.

10. Hoshing UA, Patil S, Medha A, et al. Comparison of shear bond strength of composite resin to enamel surface with laser etching versus acid etching: An in vitro evaluation. J Conserv Dent 2014;17(4):320-324. DOI: 10.4103/0972-0707.136438. 
11. International Standardization Organization. Dental materials - testing of adhesion to tooth structure. ISO/TS 11405. 2014; 1-17.

12. Zamataro CB, Ana PA, Benetti C, et al. Influence of Er,Cr:YSGG laser on $\mathrm{CaF}_{2}$-like products formation because of professional acidulated fluoride or to domestic dentifrice application. Microsc Res Tech 2013;76(7):704-713. DOI: 10.1002/jemt.22221.

13. Artun J, Bergland S. Clinical trials with crystal growth conditioning as an alternative to acid-etch enamel pretreatment. Am J Orthod 1984;85(4):333-340. DOI: 10.1016/0002-9416(84) 90190-8.

14. Ana PA, Velloso WFJr, Zezell DM. Three-dimensional finite element thermal analysis of dental tissues irradiated with Er,Cr:YSGG laser. Rev Sci Instrum 2008;79(9):093910. DOI: 10.1063/1.2953526.

15. Benetti C, Ana PA, Bachmann L, et al. Mid-infrared spectroscopy analysis of the effects of erbium, chromium:yattrium-scandiumgallium-garnet ( $\mathrm{Er}, \mathrm{Cr}$ :YSGG) laser irradiation on bone mineral and organic components. Appl Spectrosc 2015;69(12):1496-1504. DOI: 10.1366/14-07726.

16. Reynolds IR. A review of direct orthodontic bonding. Br J Orthod 1975;2:171-180. DOI: 10.1080/0301228X.1975.11743666.
17. Leão Filho JC, Braz AK, de Souza TR, et al. Optical coherence tomography for debonding evaluation: an in-vitro qualitative study. Am J Orthod Dentofacial Orthop 2013;143(1):61-68. DOI: 10.1016/j. ajodo.2012.08.025.

18. Mahdian M, Salehi HS, Lurie AG, et al. Tissue characterization using optical coherence tomography and cone beam computed tomography: a comparative pilot study. Oral Surg Oral Med Oral Pathol Oral Radiol 2016;122(1):98-103. DOI: 10.1016/j.00oo.2016.03.021.

19. Chan $\mathrm{KH}$, Tom $\mathrm{H}$, Darling $\mathrm{CL}$, et al. A method for monitoring enamel erosion using laser irradiated surfaces and optical coherence tomography. Lasers Surg Med 2014;46(9):672-678. DOI: 10.1002/ Ism.22285.

20. Rajagopal R, Padmanabhan S, Gnanamani J. A comparison of shear bond strength and debonding characteristics of conventional, moisture-insensitive, and self-etching primers in vitro. Angle Orthod 2004;74(2):264-268. DOI: 10.1043/0003-3219(2004)074<0264:ACOSB $\mathrm{S}>2.0 . \mathrm{CO} ; 2$

21. Bishara SE, VonWald L, Lafoon JF, et al. Effect of a self-etch primer/ adhesive on the shear bond strength of orthodontic brackets. Am J Orthod Dentofacial Orthop 2010;119(6):621-624. DOI: 10.1067/ mod.2001.113269. 